\title{
A Tuned Value Chain Model for University Based Public Research Organisation. Case Lut Cst.
}

\author{
Vesa Karvonen',Vesa Karvonen²,Andrzej Kraslawski ${ }^{3}$
}

\begin{abstract}
The Porter's value chain model was introduced for strategic business purposes. During the last decades also Universities and University based institutes have started to use actions similar to private business concepts. A University based institute is not independent actor like company but there are interest groups who are expecting them to act like they would be. This article discusses about the possibility of utilize tuned value chain to public research organizations (PRO). Also the interactions of tuned value chain model to existing industrial network are discussed. The case study object is the Centre for Separation Technology (CST) at Lappeenranta University of Technology (LUT) in Finland.
\end{abstract}

Keywords: value chain; public research organization; research collaboration.

'Vesa Karvonen, Dr., Director of LUT CST

${ }^{2}$ Matti Karvonen, Dr., Researcher, Department of Industrial Management, LUT

${ }^{3}$ Andrzej Kraslawski, Professor, Systems Engineering, LUT 


\section{Background}

From direct technology push we have moved through knowledge era (Landry et al., 2006) to innovation methodology (Hansen and Birkinshaw, 2007). The importance of implementation value strategy through the value chain has been studied (Walters and Lancaster, 2000) as well as market aspects of the same thing (Grunert et al., 2005). Mathematical models have been created to define value chain (Ropera et al., 2008).

There are lots of research papers about the nature of public research organizations (PRO) and their relations with industry. The research covers many angles from ethical dilemmas of university-company collaboration (Kenney, 1987) to the university research collaboration (Starbuck, 200I) in general, case study from Germany (Rohrbeck and Arnold, 2006) in selected industry and technology transfer (Lee, 1996).

The profile of public laboratories (Joly and Mangematin, 1996) gives good background as well as paper concentrated to public research organization and knowledge infrastructure (Dalpé and Ippersiel, 1999). Many institutes are operating like private companies (Etzkowitz, 2003) or business units but there are some differences.

The value chain plays also role in quality and innovation systems (Prajogo et al., 2008). University-company relations are today linked as part of the innovation system (Perkmann and Walsh, 2007) and also vice-versa situation in universitycompany relation has been studied (Orlikowski and Barley, 200 I). The impact of transaction costs of collaborative academic research has been studied (Landry and Amara, 1998) and the impact of knowledge transfer from public research organization (Gardner et al., 20l0).

There are research papers covering the role strain (Boardman and Bozeman, 2007), effective university-industry interaction (Barnes et al., 2002), market approach (Mindruta, 2008) and research collaborations of university research centers (Boardman and Corley, 2008). The development of university-industry collaboration has been interest area for research (Santoro and Betts, 2002) as well as the processes and performance in this relation Johnson and Johnston, 2004).

Innovation approach is studied a lot in this environment. The links between customer relationships of PRO and technological innovation (Nordberg et al., 2003), importance of boundary crossing (Kaufman and Tödtling, 200I) and the impact to regional innovation system (Fritsch and Schwirten, 1999).

Many investigations of PRO's impact on the national level in
Finland has been executed like the transition of public research and technology organizations (Loikkanen et al., 20I I) and the evaluation practices in public research organizations (Lähteenmäki et al., 2006).

Because the interest of this study is closely linked to chemical engineering (and any other capital intensive industry where the actions are similar) the studies of Kannegiesser (2008) are essential.

Bin and Salles-Filhoa (2012) studied the contributions to a methodological framework in science, technology and innovation management and an interesting case study from Brazilian university where the focus was orientation towards sustainable innovation is reported by Löbler et al. (2012).

\section{Research framework}

It is widely recognized that technological innovation plays a central role in the long-run economic growth of a social system and that emerging technologies. The Triple Helix model, theorized by Etzkowitz and Leydesdorff (Leydesdorff and Etzkowitz, 1996), suggests that in a knowledge-based society the boundaries between public and private sector, science and technology, university and industry are increasingly fading, giving rise to a system of overlapping interactions which did not previously exist. In practice the model is seen for example as universities are performing tasks that were formerly assigned to firms and vice versa. While the academic work is being redirected towards commercial applications, industry-university collaboration is becoming a critical issue; and wider industrial and political interests are integrated into the planning and organization of university research. The Triple Helix thesis states that the university can play an enhanced role in innovation in increasingly knowledge-based societies. Therefore academic researchers have to take into account the impacts of the scientific outputs of their work onto industry, and at the same time researchers working in industry need to be up-dated on the evolutionary developments of science. (Leydesdorff and Etzkowitz, 2000; Ughetto, 20II)

Patent markets can be considered as an example in terms of three coordination mechanism because of the "social contract" implicit in the patent system. In Figure I, patents are considered as positioned in terms of three coordination mechanism of I) wealth generation on the market by industry, 2) legislative control by government, and 3) novelty production by academia (Leydesdorff, 2012). Whereas patents are output indicators science and technology, they function as input into economy as others can learn from it and improve upon it. Their main function, however, is to provide legal protection for intellectual property. Leydesdorff, 2012 presents patents as events in a knowledge-based economy

ISSN: 07 I8-2724. (http://www.jotmi.org)

Journal of Technology Management \& Innovation @ Universidad Alberto Hurtado, Facultad de Economía y Negocios. 
Figure I: Patents as events in the three-dimensional space of Triple Helix interactions (Leydesdorff, 20I2)

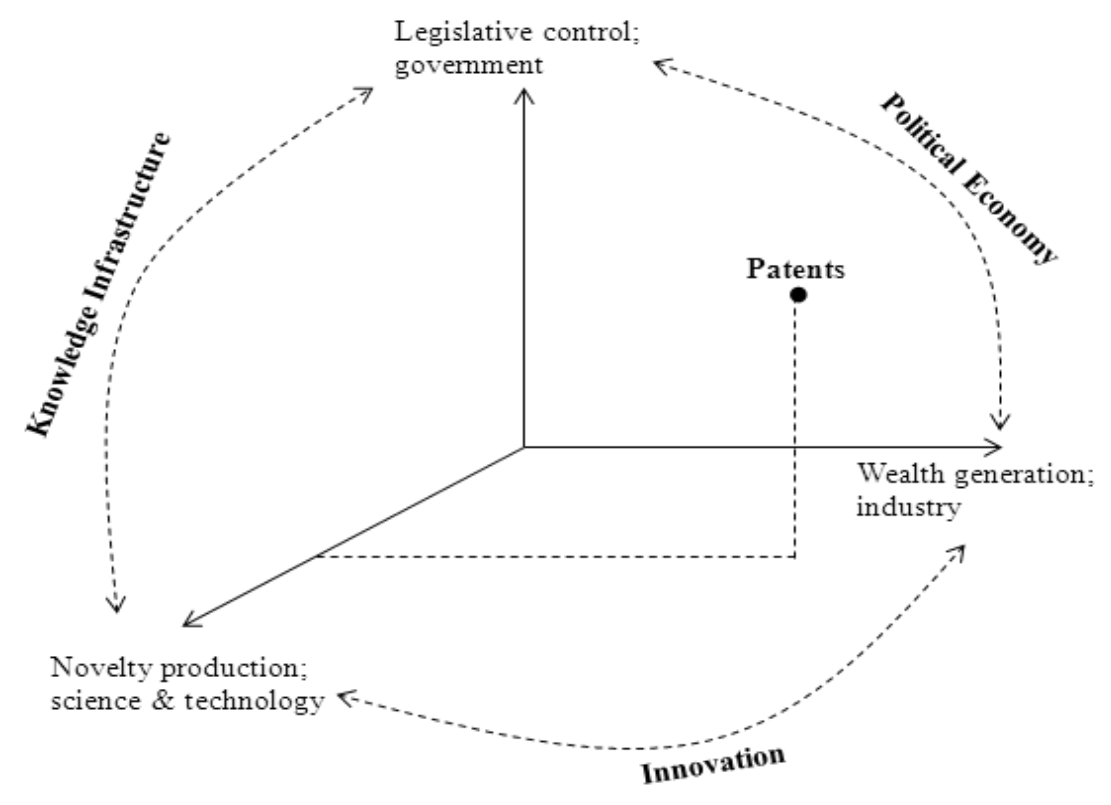

which can be positioned in this three-dimensional space of industry, government and academia (Figure I).

Naturally, the Triple Helix model does not exclude focusing on two of the three dynamics -for example, in studies of university-industry relations. However, one can expect more interesting results by studying the interactions among the three sub-dynamics or the third dynamics should at least be declared as another source of variation. (Leydesdorff and Etzkowitz, 2000)

\section{Value chain approach}

Michael Porter introduced value chain model (Porter, 1985). The classic Porter value chain approach is suitable for many industrial processes and manufacturers. Porter himself has reported of case studies carried out in different industries of his strategy and value chain. The value chain model can also be used for service companies because the basic elements are similar to industry.

The classic Porter model shows the value chain in original format, Figure 2.

\section{Institutional frame; Case study public research organization}

\section{The Lappeenranta University of Technology - LUT}

The Lappeenranta University of Technology (LUT) is founded in 1969. LUT has three faculties; technology, technology management and school of business. LUT has about 5000 undergraduate students and 930 staff members.
The strategic areas of expertise are following; energy efficiency and energy market, strategic management of technology and business and scientific computing and modeling of industrial processes. The fourth is expertise in Russian affairs related to the LUT's areas of expertise.

\section{The Centre for Separation Technology - CST}

Lappeenranta University of Technology (LUT) hosts the Centre for Separation Technology (CST) which is a cooperative institution (founded in 1997) that integrates the expertise in Separation Technologies mastered by several laboratories and research groups at LUT Chemistry (Department of Chemical Engineering).

The research at CST aims at a multilevel approach covering molecular, unit operation and process levels. The molecular approach is represented in chemistry and analysis which give the solid basis to other level actions. In the unit operation level CST has focused on membrane filtration, solid-liquid separation, crystallization, ion exchange, chromatographic separation methods and extraction. On the process level CST has expertise in process intensification, simulation and systems engineering which all are required when connecting unit operations to the form of production processes. Of course, the deep understanding of chemistry and analytics gives the LUT CST tools for phenomena based research.

The research within CST is genuinely multi-disciplinary and applications of separation technologies are studied at CST can be found widely in the industry. However, regardless of the application field, the different technologies are based

ISSN: 07 I8-2724. (http://www.jotmi.org) 
Figure 2. The value chain (Porter, 1985).

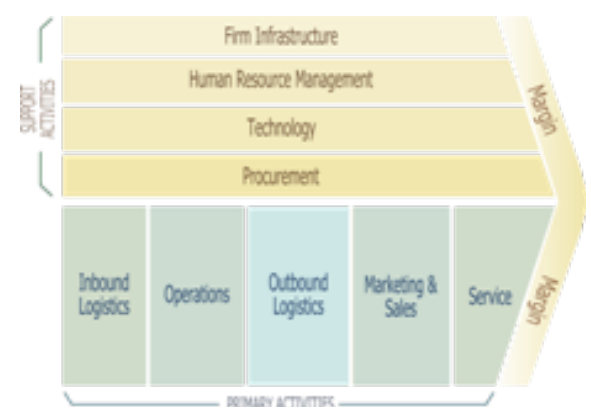

on the same basic principles and the deep understanding of chemistry and analytics. The expertise of LUT CST is based on the LUT Department of Chemical Engineering. The total staff of the department is about 85 including 10 Professors, about 50 researchers and 15 persons as technical staff.

The structure of CST is unique inside LUT organization. CST has today 25 member companies from different industries. During the last years CST has also expanded the international research member network and today the total amount of research members is 14 .

The Centre for Separation Technology has three strategic research impact areas. The first is material efficiency which means better yield from low-grade raw materials with less side flows. The second is development of energy efficient processes to the improved use of internal energy in processes. The third one is water especially different kind of treatments for raw water, process water circulation and waste water purification. The above mentioned impact areas are directly linked to LUT strategy.

\section{Collection of empirical data}

Public research organization should create added value to whole society and in this case the primary target in it is the member network of LUT CST.

The scientists have of course their own idea what this added value should be and usually it is top level academic research which leads to the dissemination of the results to the high quality academic journals.

The added value is even more difficult to measure. LUT CST executed an enquiry to the members in the spring 20I I.The material is shown in appendix I.The motivation to this enquiry was to ensure the expectations of LUT CST members and to develop activities based on enquired facts.

What are the expectations? In this study the most important question in the enquiry was number 4; "What of the following subjects are most crucial subjects to be developed in the near future in the LUT CST to create added value to your company or research institute?" The results were introduced to the Board of CST in May 20II and the subjects mentioned below where discussed.

The data is relatively small but the answerers are in the top positions in their private organizations like CEO, CTO, R\&D-director level etc. The answerers from research and academic world are mostly Professors and Heads of the departments. In this case study the data is based on excellent expertise and long term personnel history in this field.

The five most important subjects were:

I. Innovativeness. The industrial partners expect to get novel openings from the University. Because of the complexity of many processes it is not anymore possible to solve existing and coming problems only by using one separation method or unit operation to this task.

2. Research collaboration in general. This means active collaboration with the R\&D departments of member companies.

3. International networks. Industry is expecting to see international collaborations between universities especially on the international level. To achieve the best results the links between the leading universities are required.

4. Collaboration between different research groups inside LUT. This message was clear. The research groups in LUT are relatively small compared to bigger universities. To tackle bigger tasks diversified expertise is needed. Also in many cases it would be relevant to combine experts from different research groups to study one issue.

5. Project development. In many businesses the R\&Dfunds are bounded in the budget to selected actions for next year. This is challenge to PRO to inform all industrial members of the novel project ideas in time. Also the delay in getting partial finance agreement from industry has increased. All would like to have time enough to fit these requirements to annual planning. 
Figure 3.The results of the LUT CST member enquiry. (Appendix I).

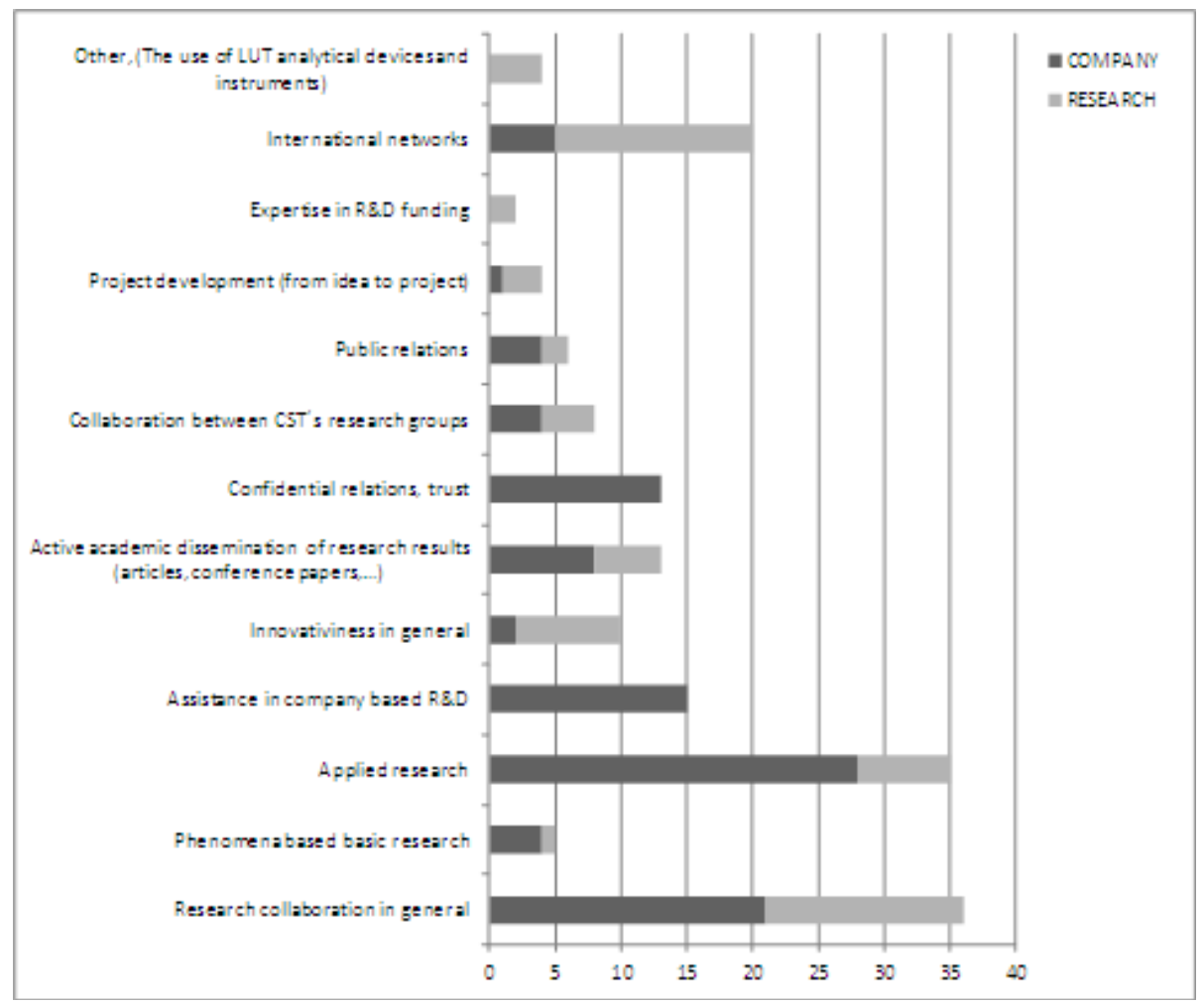

\section{Analysis}

Because the value creation is the focus for every PRO it was natural trying to transfer the results of the enquiry into familiar form of classic business management tool. In this case the classic value chain model by Porter was chosen to this purpose.This model is not novel but it is simple.There is also embedded characteristic which helps PRO to fractionize it's activities to different parts. The support activities are mostly taken care by the host university but the primary activities and optimizing is interesting.

How this frame suits to university based research institute where the "brains" is the core factor in production and processes in creating new research results vary a lot case by case? Some examples of differences: procurement and inbound logistics are closely related to raw material and subcontractor management which are not the core activities in scientific work. The product of research is merely nonphysical and thus there is no need for outbound logistics.

The "reason to live" function of private company is to create margin and profit to the share holders. In state university like LUT margin or profit is suitable but the success of the institute is mostly measured by academic results (articles, conference papers, master graduates, doctor graduates, etc.). Of course this basic academic function must be profitable enough to ensure continuous development.

ISSN: 07 I8-2724. (http://www.jotmi.org) Journal of Technology Management \& Innovation (c) Universidad Alberto Hurtado, Facultad de Economía y Negocios.
The better description of the value chain to the academic environment needs the renaming of the original one. In Figure 4 it is shown the value chain of university based research institute in case study LUT CST.

Why to rename the Porter's original value chain in Figure 2? The answer is clear. The goal is to localize this concept suitable to the academic world of technology research. To get more accurate picture of the value chain system to this case it is relevant to rename the subjects of the original Porter frame. Support activities:

Firm infrastructure. This is valid when we are discussing about independent companies but it does not cover the situation when research unit or institute is essential part of the university. That is the reason why the term research infrastructure is more relevant in this case. To the research organization this means more than firm infra alone. High level research needs modern research infrastructure. In this case, in separation technology research, the required equipment and instruments are related to chemical and process engineering and chemistry. It is easy to understand that it is very capital intensive to establishing and updating this kind of facilities. Facilities, maintenance of laboratory equipment and many other activities are organized by parent University. 
The human resource management can be in this case replaced by expertise development and human resources management. To every expert organization the development of expertise is the core factor.Via new research it is possible to develop novel unique skills and expertise which are impossible to loan, borrow or simulate in the short term. This is the most important advantage to every expert organization. The quantity and quality of research power appear in the form of expertise of individuals. In the long run it is essential to develop the expertise of individuals to remain on the top level. On the other hand it is well known that management of expert organization to create innovative team spirit is challenging.

The administration is better term this case than technology. To achieve planned target in research oriented environment the administration (ICT, financial administration, legal advising activities related to IPR and contracts and other non-engineering support activities) are organized by parent University.

Procurement can be transferred into project funding arrangements. In many Universities (like in Finland in the field of engineering/technology research) every research unit has to get at least $50 \%$ of the annual budget out of the "free market". In practice this means national funding organizations, direct EU-funding and of course research subcontracting with the private companies. Practically it is project based and relatively short term (usually max. 3 years). This fact causes continuous need for project development and "idea selling" to partners and financers. This phase must be very proactive. Otherwise there might be lack of funding periods when it is impossible to keep the best experts in this institute. The delays in fund collection are long and hit rates are difficult to estimate.

\section{Primary activities:}

To the University unit the research is the most important thing. Because academic results are measured by the amount of the research the term inbound logistics is not needed. The primary activities process starts with the idea generation and development. As mentioned before the fundraising is essential and the success in it can be later measured by the amount of the refereed articles, international conference papers graduated masters and doctors is the core thing. To the service function to the industry this is also important because it gives to the institute or university scientific backup. Idea generation consist of development of novel research challenges into form of project theme.The basic ideas to this sub activity come both from researchers and industry where intensive networking and industrial collaboration is crucial and together they constitute idea portfolio. The industrial partners usually like to comment ideas and check the industrial relevance of new research themes. On the other hand this is important phase to preliminary negotiations to get partial financing from industry.

Research. Normally the research itself runs well according to the accepted research plan. The staff of LUT CST has excellent routine of this task. The role of the CST is merely to boost the task and ensure that research can be executed with modern equipment. The research can be categorized into the three classes by the publicity and IPR of the results: public, semi-public and industrial subcontracting. In the classic public research all results are public and the IPR belongs to the researcher and University. In the semi-public format industrial partners has usually to partial financing role which means that they have also limited rights to IPR. This case does not normally cause any limits to result dissemination.

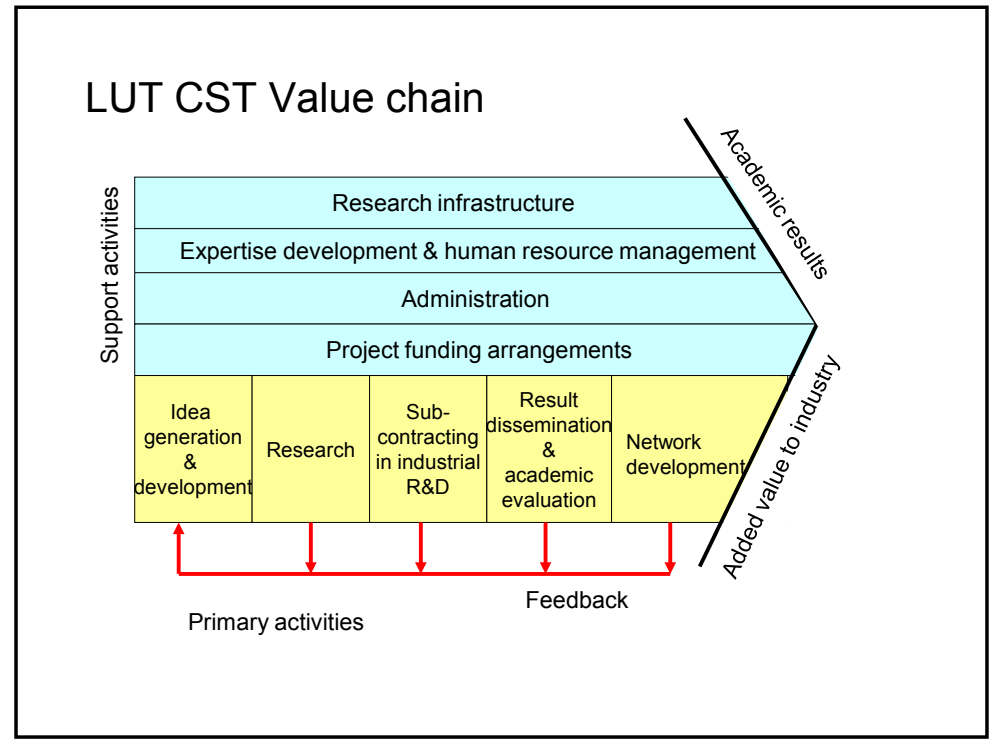

Figure 4. The tuned value chain model, case LUT CST.

ISSN: 07 I8-2724. (http://www.jotmi.org)

Journal of Technology Management \& Innovation (C) Universidad Alberto Hurtado, Facultad de Economía y Negocios. 
The research subcontracting role is demanding because the private company in the role as financier owns the IPR but in most cases dissemination process runs normally but sometimes there are some delays because of the simultaneous IPR process.

To the research unit in university the outbound logistics does is not relevant. The output of the research is mostly in "brainpower" which does not need a special logistics. The participation of industrial R\&D as a subcontractor is more important term. This action creates new connection (measured by practical relevance of the research) and in the most cases it is possible to make also academic output out these studies. This research institute participates to industrial R\&D projects as a subcontractor. Even these operations are based on the trust (usually close to novel IPR and business possibilities) it is normally possible to use this material also for academic publications. These actions are based on confidential relations and in most cases confirmed by bilateral agreement (company / LUT). One form of the subcontracting is technology transfer from basic research to applications.

The Porter's function of marketing and sales are not familiar terms in many universities. As a University research unit it is important to take care of the academic development. In every case one university unit is not strong enough to cover all the needs alone. Especially with this case networking collaboration global science is more than expected.

The dissemination of academic credits in the traditional way is measured by the Ministry of Education in Finland. Of course this is a classic meter but today this is more and more important also for the industrial partners. For them it is a benefit to collaborate with an institute with high academic references because many industrial partners don't have power enough to carry out basic research and in many cases it is not their role at all. They are merely interested in applied research which is close to the applications and profit. Result dissemination in academic scene is basic function of university. This task also implements the quality control function because as well known the top level research journals and international conferences wants to ensure the quality of the publications. Vice versa this action increases co-operation to the global academic world which supports networking.

The service action of the Porter's original scheme can be substitute by network development. Today is relevant to say that any university can't make top research without active international research collaboration. As well this section covers the interest group management (how to create added value to the existing network). Networks are connected to all elements of primary actions. It links together the whole process and adds all interest groups into the produc- tion. But it has also other functions. In many research challenges it divides the project into subprojects or tasks which can be carried outside LUT in CST member network. One form of the networking is public relations in form of CST Board meetings (three times a year) and CST Bulletin (four numbers out annually in PDF-format). Also hosting annual international workshops and seminars gathering scientists and participants from industry together evolve and boost the existing network and even expand it. One direction of the networking is financiers. CST likes to give preliminary information to them of future needs and trends in separation technology research.

In the Figure 4 the value chain output is not margin like in the original Porter figure but novel academic results and added value to industry. This formulation suits better to university based institute. The classic academic output in the case of LUT and LUT CST are research education and societal interaction. The nature of added value to the industrial partners is studied with an enquiry and the results are discussed later in this article.

\section{The feedback operations}

In the Figure 4 there is a feedback connection which shows the links between different operations on the primary action level. They can be described alone but actually primary actions create innovative processes where clear interactions between different actions can be found including the feedback effect. The feedback action varies case by case but in all cases it is crucial to use the information from the later steps in the beginning of the process. This is also one form of the quality control. This way it is easy to improve to performance during the whole process, learn from mistake and implement good practices immediately.

\section{Vertical and horizontal connections of the tuned value chain}

The value chain does not live independent life. It has connections both on the vertical and horizontal levels. In the vertical connection level; how does our value chain align vs. company value chain and R\&D activities? LUT CST is dealing with many companies and industries. It is not simple to execute the vertical integration of LUT CST value chain into the all value chains of our member companies.

LUT CST member companies can be divided into the three categories. The first category is the technology providers (like Outotec in mining and metallurgy,Andritz and Metso in pulp, paper and bioenergy). They are companies who are offering both technology (knowledge) and process equipment to the customers. The second group is the process owners (like StoraEnso, UPM-Kymmene in pulp and paper busi- 
ness and Talvivaara in mining) who operate the processes but don't themselves build the equipment. Of course the technological knowledge is always in the very important role in these cases. The third class is expertise provider (consultancy companies like Filter-Ability and Provenor) and other Universities and research institutes.

\section{Discussion; from value chain to interactions in value network}

To assume that all these three above mentioned categories are having their own value chain like Porter's original (shown in Figure 2) what kind of interactions they will have to CST's tuned value chain (shown in figure 4)?

The differences shown in the Table I base on following facts. Thinking about the original Porter's value chain frame it is divided into the two kinds of activities, support activities and primary activities. This explains the different impact of CST impact on members' value chain. In all cases the impact to the support activity technology and network development are obvious. In case of the effect to the primary actions the situation differs. To the technology provider it is more important to use novel research results (usually created together in common R\&D projects) to boost the marketing and sales active where as the situation with process owners where it is more important to effect to the operations (to reach top quality with high operating time ratio). With ex- pertise providers service is very important issue because this business needs the continuing renewal of expertise.

Vice versa. What is the feedback information from CST's members and for what parts it is effecting in the tuned value chain model? The idea development is the common thing; it is good to get information of existing or coming problems of processes to get practical relevance for the idea development and titles for the new research projects. Project funding, subcontracting industrial R\&D and network development are essential from technology provider and process owner categories. This offers possibility for continuous development and partnership; ideas can turn into the action. With member universities and research institutions it is possible (in most cases) to execute common public research projects which is not possible with industrial partners. In most case the IPR-case limits the so called classic free science.

There are many other research institutes and it is possible to have different opinions in strategic lines. This means that different research units can be seen like strategic business units (SBU). It is important to create a real connection between LUT level strategy and to value chains of separate units to avoid confusion.

One way to develop this vertical integration is the segmentation. Is it possible to use the service packaging of CST

\begin{tabular}{|l|l|l|}
\hline \multicolumn{1}{|c|}{ Category } & \multicolumn{1}{|c|}{ Input to CST } & \multicolumn{1}{c|}{ Output from CST } \\
\hline Technology provider & $\begin{array}{l}\text { Idea development } \\
\text { Project funding } \\
\text { Subcontracting industrial R\&D } \\
\text { Network development }\end{array}$ & Technology \\
& $\begin{array}{l}\text { Idea development } \\
\text { Project funding } \& \text { Sales } \\
\text { Subcontracting industrial R\&D } \\
\text { Network development }\end{array}$ & \\
\hline Expertise provider & $\begin{array}{l}\text { Idea development } \\
\text { Research } \\
\text { Network development }\end{array}$ & Technology \\
\hline
\end{tabular}

Table I.The interactions and targets between CST's tuned value chain and Porter's original format of CST's members.

ISSN: 07I 8-2724. (http://www.jotmi.org)

Journal of Technology Management \& Innovation (C) Universidad Alberto Hurtado, Facultad de Economía y Negocios. 
expertise and create different impact for members dealing with different business? This action would offer more specified and more business oriented touch to members. The threat is to lose at the same time the role in technology transfer from one business to other. Actually the rate of integration is interesting. Is it possible to develop model which will deepen the collaboration and at the same time clarify the roles of university and member company R\&D department?

One solution (in principle) is to segment members by geographical means. This is not relevant option in so small country like Finland. In most cases the most important R\&D centers are still located in Finland even many companies are global players.

\section{Conclusions}

The classic Porter value chain includes all those elements which are adequate also for research organization. The importance of elements vary in this case compared to traditional industrial or service company and thus the renaming of those elements helps to get the right scope of support and primary actions. Of course depending of the research field there might be a need to create variations based on the tuned value chain model introduced in this paper.

It is clear that value chain model is useful also to other research institutes not only to this case study object. It is a tool in the strategic planning and management to keep the actions in the focus.

In the tuned value chain the feedback operation linking primary actions helps to understand the research as a process. The output of the process has usually more value than only the academic one.This emphasizes the total research impact.

The output of the value chain is interesting in this case. It can be measured by classic way via the academic output (research, education, societal interaction). The more interesting window opened by analyzing the results of CST member enquiry about the expectations of added value. The industrial partners expect to get following benefits from PRO: innovativeness, research collaboration in general, international networks, collaboration between different research groups inside LUT and project development.

Combining tuned value chain with the "original" value chain it is possible to describe the effects in value chain network; which actions/operations are creating input/output effects and where. In this paper three level approaches were used by categorizing members into the groups; technology provider, process owner and expertise provider.
Finally the results of LUT CST external member enquiry was discussed in the value chain frame.

The tuned value chain model looks to be important tool in understanding the basic function of research institute. It also helps to define the most important information transaction in generation the added value.

The future research needs based on this paper can be divided into two categories. It would be very interesting to study the suitability of this tuned value chain model in with some other research institutes.

\section{References}

AURANEN, O., Nieminen, M. (20I0). University research funding and publication performance - An international comparison, Research Policy, 39, 822-824.

BARNES, T., Pashby, l., Gibbons, A. (2002). Effective University - Industry Interaction: A Multi-case Evaluation of Collaborative R\&D Projects, European Management Journal, 20 (3), 272-285.

BIN, A., Salles-Filhoa, S. (20I2). Science, Technology and Innovation Management: Contributions to a Methodological Framework, J.Technol. Manag. Innov., 7 (2), 73-85.

BOARDMAN, C., Corley, E. (2008). University research centers and the composition of research collaborations, Research Policy, 37 (5), 900-913.

BOARDMAN, C., Bozeman, B. (2007). Role strain in university research centers, The Journal of Higher Education, 78 (4), 430-463.

DALPÉ, R., Ippersiel, M-P. (1999). Public Research Organizations in the Knowledge Infrastructure, http://www.utoronto. ca/isrn/publications/WorkingPapers/Working99/Dalpe99_ PRO.PDF

ETZKOWITZ, H. (2003). Research groups as 'quasi-firms': the invention of the entrepreneurial university, Research Policy, 32 (I), 109-121.

FRITSCH, M., Schwirten, C. (1999). Enterprise University Co-operation and the Role of Public Research Institutions in Regional Innovation Systems, Industry and Innovation, 6 (I), 69-83.

GARDNER, P.L., Fong,A.Y., Huang, R.L. (20I0). Measuring the Impact of Knowledge Transfer from Public Research Organizations: A Comparison of Metrics Used Around the World, International Journal of Learning and Intellectual Capital, 7 (3/4), 318 - 327. 
GRUNERT, K., Jeppesen, L.F., Jepersen, K.R., Sonne, A-M. (2005). Market orientation of value chains. A conceptual framework based on four case studies from the food industry, European Journal of Marketing, 39 (5/6), 428-455.

HANSEN, M.T., Birkinshaw, J. (2007). The Innovation Value Chain, https://blog.itu.dk/KMP-E2008/files/2008/08/theinnovationvaluechain.pdf

JOLY, P.B., Mangematin, V. (1996). Profile of laboratories, industrial partnerships and organization of R\&D: the dynamics of relations with industry in a large research organization, Research Policy, 25 (4), 90I-922.

JOHNSON, W.H.A., Johnston, D.A. (2004). Organisational knowledge creating processes and the performance of university-industry collaborative R\&D projects, International Journal of Technology Management, 27 (I), 93 - I I4.

KANNEGIESSER, M. (2008). Value Chain Management in the Chemical Industry: Global Value Chain Planning of Commodities, Heidelberg: Physica-Verlag.

KAUFMANN,A.,Tödtling, F. (200I). Science-industry interaction in the process of innovation: the importance of boundary crossing between systems, Research Policy, 30, 79I-804.

KENNEY, M. (1987). The Ethical Dilemmas of University-Industry Collaborations, Journal of Business Ethics, 6, I27-I 35.

LÄHTEENMÄKI-SMITH, K., Hyytinen, K., Kutinlahti, P., Konttinen, J., (2006). Research with an impact. Evaluation practises in public research organisations. VTT Research notes 2336. http://www.vtt.fi/inf/pdf/tiedotteet/2006/T2336.pdf

LANDRY, R., Amara, N., Pablos-Mendes, A., Shademani, R., Gold, I. (2006). The knowledge-value chain: a conceptual framework for knowledge translation in health, Bulletin of the World Health Organization, 84 (8), 592-602.

LANDRY, R., Amara, N. (1998). The impact of transaction costs on the institutional structuration of collaborative academic research, Research Policy, 27, 901-913.

LEE, Y.S. (1996). Technology transfer' and the research university: a search for the boundaries of university-industry collaboration I, Research Policy, 25, 843-863.

LEYDESDORFF, L., Etzkowitz, H. (1996), Emergence of a Triple Helix of university-industry-government relations, Science and Public Policy, 23, 279-286.

LEYDESDORFF, L. and Etzkowitz, H. (2000), The dynamics of innovation: from National Systems and 'Mode 2' to a Triple
Helix of university-industry-government relations, Research Policy, 29 (2), 109-123.

LEYDESDORFF, L., \& Meyer, M. (20I0). The Decline of University Patenting and the End of the Bayh-Dole Effect. Scientometrics, 83(2), 355-362.

LEYDESDORFF, L. (2012). The Triple Helix of UniversityIndustry-Government Relations, http://www.leydesdorff.net/th I / th I 2.pdf

LÖBLER, M.L., Gomes da Silva, B., Pozzobon, D.M., Gomes, C.M. (20I2). Strategic Orientation Towards Sustainable Innovation: A Case Study in a Brazilian University, J. Technol. Manag. Innov., 7 (2), 196-205.

LOIKKANEN, T., Hyytinen, K., Konttinen, J., (20II). Public research and technology organizations in transition - the case of Finland, Science, Technology \& Society, 16 (I), 75-98.

MINDRUTA, D. (2008). Value creation in university-firm research collaborations: a matching approach, http://papers. ssrn.com/sol3/papers.cfm?abstract_id=|35| 904

NORDBERG, M., Campbell, A., Verbeke, A. (2003). Using customer relationships to acquire technological innovation. A value-chain analysis of supplier contracts with scientific research institutions. Journal of Business Research, 56, 7II719.

ORLIKOWSKI,W.J., Barley, S.R. (200I). Technology and Institutions:What Can Research on Information Technology and Research on Organizations Learn from Each Other? Management Information Systems Quarterly, 25 (2), I 45- 165.

PERKMANN, M., Walsh, K. (2007). University-industry relationships and open innovation: towards a research agenda, International Journal of Management Reviews, vol. 9 (4), 259280.

PORTER, M. (1985). Competitive Advantage: Creating and Sustaining Superior Performance, New York, NY, The Free Press.

PRAJOGO, D.I., McDermott, P., Goh, M. (2008). Impact of value chain activities on quality and innovation, International Journal of Operations \& Production Management, 28 (7), 615-635.

ROHRBECK, R., Arnold, H., M. (2006). Making universityindustry collaboration work - a case study on the Deutsche Telekom Laboratories contrasted with findings in literature, ISPIM 2006 Conference "Networks for Innovation" I th14th June 2006, Athens, Greece. 
ROPERA, S., Dub, J., Loveb, J.H. (2008). Modelling the innovation value chain, Research Policy, 37, 961-977.

SANTORO, M.D., Betts, S.C. (2002). Making industry-University partnerships work, Research Policy, 3 I (7), I I63-I I 80.

STARBUCK, E. (200I). Optimizing University research collaborations, Research Technology Management, 44 (I), 40-45.

UGHETTO, E. (2007). Foresight as a triple helix of industry, university and government relations, Foresight, 9 (5), I4-22.

WALTERS, D., Lancaster, G. (2000). Implementing value strategy through the value chain, Management Decision, 38 (3), 160 - 178.

\section{APPENDIX}

The background of this enquiry:

Number of answers:

- industrial members, 8 (34\% of all industrial mem-

bers)

- research members, 7 (58\% of all research mem-

bers )

- Totally 15 answers which covers $43 \%$ of all mem-

bers

Sources of errors in this enquiry:

- Was the contact person in member company/institute relevant?

- How well the answerer knows the whole situation on behalf of the whole organization?

- Limited number of answers (absolute amount) but tolerable in per cents 


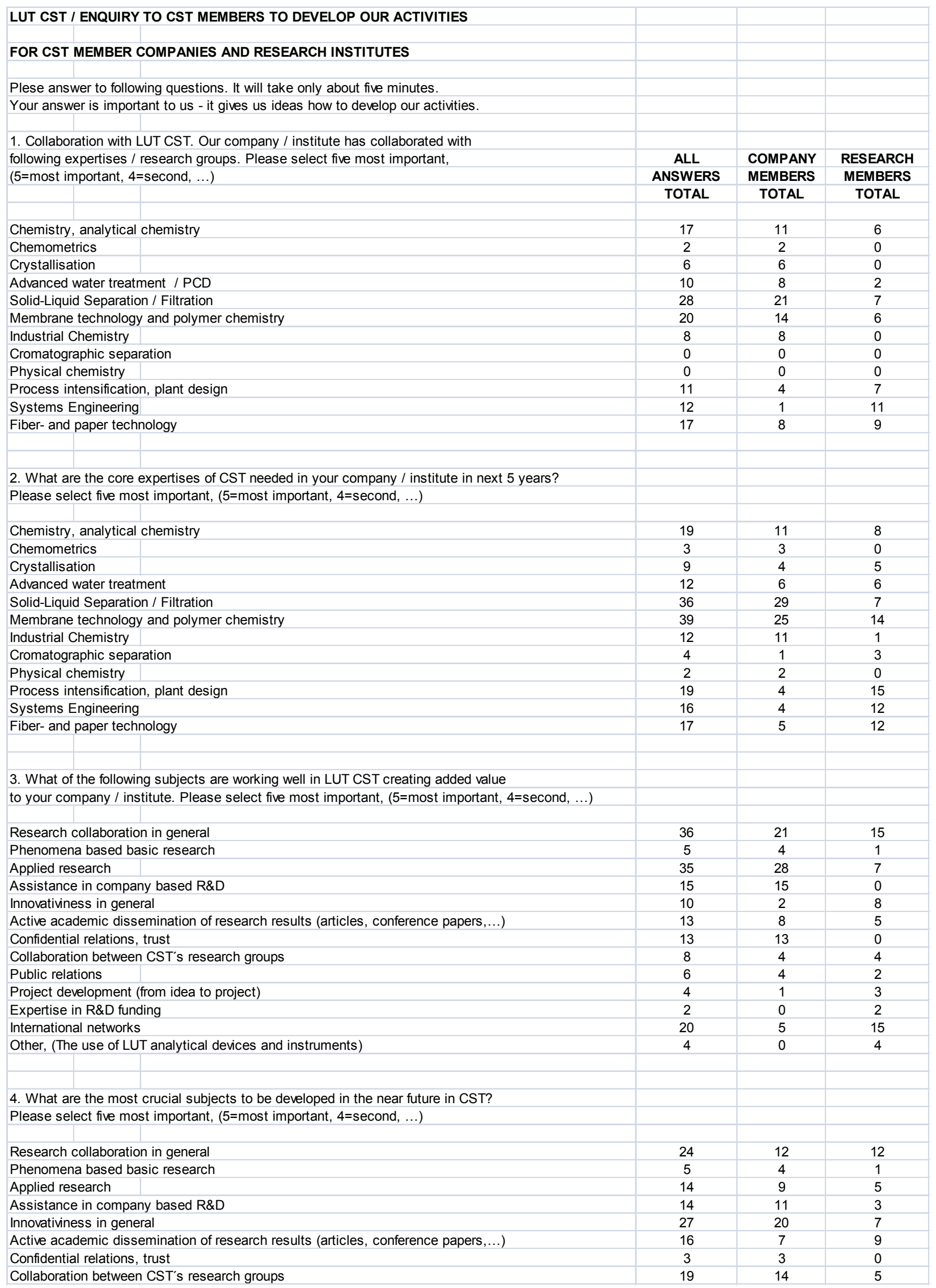

ISSN: 07 I8-2724. (http://www.jotmi.org) 